\title{
Lessons of the Prevention of the Mother to Child Transmission (PMTCT) of HIV in the Biyem-assi District Hospital From 2010 to 2015
}

\author{
Article Judith Maka1, Patrice Takam Soh2, Robinson Enow Mbu3, Vladimir Pente \\ Yamou4 \\ ${ }^{I} M D, M P H$, PhD student in Public health, Chief of the International Immunization's center \\ of Yaoundé \\ ${ }^{2}$ Doctor in Statistics, department of mathematics, University of Yaoundé I \\ ${ }^{3}$ Professor of obstetrics and Gynaecology, \\ Department of Family health, Ministry of Public Health Cameroon \\ ${ }^{4}$ Epidemiologist \\ Email: judiithmani70@hotmail.com1,ptakamsoh@yahoo.fr2,rmbu2000@yahoo.com3, \\ vladpent@yahoo.fr4
}

\begin{abstract}
Introduction: Aids is a pandemic. In 2016, according to UNAIDS, the number of people living with HIV is 36.7 million. New infected children represent 160 000, mostly via their HIV positive mothers during pregnancy, delivery or breastfeeding. Since 2010, different political decisions were adopted and later the option $B+$ to reduce the transmission rate. Little is known about their implementation at the operational level in the Center Region of Cameroon.

Method: We aimed to draw the evolution of PMTCT services in the Biyem-Assi District Hospital. From 01 to 26 April 2016, through a descriptive retrospective cross sectional study, we used registers of the consultation (pregnant women, children) and HIV test from 2010 to 2015, Excel software to compile data, describe tables and figures.

Results: We found a good response rate of the HIV screening test in the ANC unit. $99.88 \%$ in 2015 compare to $95.93 \%$ in 2010. The number of pregnant women newly screened in the delivery room was increasing, 99 in 2013, 279 in 2014 and 786 in 2015. Among these pregnant women newly screened, an increasing number of positive cases; from 2 in 2010 to 10 in 2015. There was a high rate of lost to follow up of HIV-exposed infants (HEI).

Conclusion: Training of health care workers is a priority for the early infant diagnosis of HIV. Further studies are needed to reduce the lost to follow up, to screen and treat the HEI registered in the delivery rooms.
\end{abstract}

Keywords: PMTCT, HEI, option B+, Biyem-Assi District Hospital, HIV, AIDS.

\section{Introduction}

AIDS is a pandemic. In 2016, 2.1 million [1.7million - 2.6 million] children aged from 0 to 14 years worldwide were infected with HIV, and 120000 [ 79000 - 160 000] died from AIDS related illnesses (UNAIDS, 2017). The majority are in sub-Saharan Africa. Among the newly infected children, most of them are infected via their HIV positive mothers during pregnancy, childbirth or breastfeeding (WHO, 2016). Effective interventions are engaged since 2010 around the world to eliminate new infections among children and keeping their mothers alive (WHO, 2010). Before the implementation of option A in 2011, there was no provision of prophylaxis for PMTCT. With "Option A" PMTCT interventions relied on maternal CD4 count. In early 2013, "Option B+" was started, immediate and lifelong ART was given to HIV positive pregnant mother irrespective of CD4 count with an enhanced treatment for the baby.

Strong public health politics is one of the good factor for the PMTCT success (Moodley, Moodley, Sebitloane, Maharaj, \& Sartorius, 2016); In a systematic review of peer-reviewed English and Chinese literature during 2003 - 2011, among 113 publications, HIV prevalence among pregnant women in China who accessed ANC remained below $0.1 \%$; this improvement is partly due to a good investment of Chinese Government (US\$ 140 million annually) on prevention of mother - to - child transmission 
of HIV (Zeng et al., 2016). Despite some health difficulties that faced many developing countries like poverty, inequity, disorganization of medical services, low male partner involvement, resistance to the screening tests, many African countries adopted in 2010 the strong political decision for 2 time bound targets:

1. Reducing the new HIV infections among children by $90 \%$ and

2. Reducing Aids related maternal deaths by $50 \%$

And later the prevention method of option B+ (W H O, 2013).

This epidemiological concept of prevention (primary, secondary or tertiary) require the implication of the whole family members in a particular society and could have a positive impact on maternal and infant morbidity and mortality (Burton, Darbes, \& Operario, 2010), (Kashitala et al., 2015), (Hampanda, Nimz, \& Abuogi, 2017). The behavior of the pregnant women, their spouse and their family about the use of the medical service can be explained by the Health Belief Model (HBM) theory. This theory explain the steps to be considered in the process of the behavior change during the PMTCT activities : perceived severity, perceived susceptibility, perceived benefits, perceived barriers, modifying variables, cues to action, self-efficacy (Janz \& Becker, 1984). In Ethiopia, Among 398 pregnant women attending the Antenatal care, only 386 accepted the provider -initiated HIV test, with response rate of $97 \%$ and $312(80.8 \%)$ of them accepted the provider-initiated HIV testing (Abtew, Awoke, \& Asrat, 2015). A good implementation of PMTCT 'Option B+ in a resources limited setting can result in Zero HIV infection rates among HIV - exposed children, but there still a high loss to follow up rate at 6-8weeks of age (Olana, Bacha, Worku, \& Tadesse, 2016) .

In a PEPFAR report, the prevalence of HIV in Cameroon in 2013 was around 4,3\%, but remain relatively high among pregnant women $(7,6 \%)$. Since 2014 with the option $\mathrm{B}+$, the national protocol recommended in all the antenatal care settings, to provide early free HIV test (Determine and Shangai) to all pregnant women and in the delivery room (when the previous test was done in more than 3 months ago ). This may reduce the number of late diagnosis, late initiation on ART and may give a better effect on the infant outcome (Tariq, Elford, Cortina-Borja, Tookey, \& National Study of HIV in Pregnancy and Childhood, 2012). Many NGO's worked to train health care workers, giving them Awareness, knowledge, attitude and skills for a better PMTCT services (Ministry of Public Health Cameroon, 2012).

The BDH is a reference district hospital with an average of 5000 annual consultations. Among its 238 health care personnel, some are continuously trained to provide PMTCT services. Till January 2018, all the DBS sample were sending to CIRCB for PCR analysis. We aimed to show the evolution of the implementation of this program at the operational level of the health system to obtain HIV negative new born child from an HIV- positive pregnant woman. We also wanted to provide data base for further studies on this field.

To present this experience, we will explore the generalities on topic, followed by the method used and results, at the end, conclusion, recommendations and some perspectives will be given.

\section{Method}

\section{Description of site}

Cameroon is a country in Central Africa and its population in 2011 was estimated to 19406100 inhabitants according to the National institute of statistics. It is made of 10 Regions, 58 Divisions, and 360 sub-Divisions. The study was conducted in the District hospital of Biyem-assi. The Biyem-assi district Hospital (BDH) is located in the center region, in a multicultural urban setting. It is one of the biggest referral districts Hospital in Yaoundé with a variety of services provided at the operational level of the health pyramid.

\section{Study design}

We carried out a Descriptive retrospective Cross sectional study on all pregnant women followed respectively in the Antenatal care unit (ANC), the delivery room and children born from HIV positive pregnant women followed in the pediatric service from 2010 to 2015 at the Biyem-assi District Hospital (BDH). BDH is located in the center region of Cameroon, in a multicultural urban setting. It 
is one of the biggest referral district hospital in Yaoundé with a variety of health services provided at the operational level of the health pyramid. Data were collected during the period from 01 April 2016 to 26 April 2016.

\section{Data source}

We used different registers of the routinely PMTCT activities in 3 services: The Antenatal care unit, the delivery room and the HIV-exposed children followed in the the pediatric service.

\section{Data collection method}

PMTCT cascade activities were summarized in a data collection grid. This grid was composed of three sections. The section 1 helped to find out the total number of pregnant women registered in the ANC, the number of women screened for HIV, the HIV screening test response rate, the total number and the proportion of the HIV positive pregnant women. The section 2 gave the proportion of the HIV positive newly tested pregnant women in the delivery room, the total number of HIV exposed children registered in the health facility. In the section 3, we could obtain the total number and the proportion of HIV positive children among HIV-exposed children with the Polymerase Chain reaction (PCR) available after 6 weeks of life in the pediatric service.

\section{Statistical method}

Data collected were filed in the Excel software. We used descriptive analysis to calculate the frequencies, proportion of screened pregnant women, and the prevalence of HIV per year in different groups. We also obtained the proportion of the PCR results available after 6 weeks of life in the pediatric service. Figures and Graphs were designed on Excel software.

\section{Ethical considerations}

Since we were working on secondary data, no written informed consent was sought. But as a medical professional, we kept secret all information concerning HIV positive patients. An administrative authorization of the study area was obtained before the data collection in order to address recommendations for implementation. We also Kept results available in the study area.

\section{Results}

With the nurse's help, we consulted registers to collect the total number of pregnant women consulting and performing the HIV tests at the ANC unit, delivery room, and children in the pediatric service for HIV-exposed children.

\section{Response to the HIV test and the HIV prevalence in the antenatal care unit}

We found in the table below that nearly all the pregnant women who visit the ANC unit performed their HIV test in 2015 with a response rate of $99.88 \%$ compared to $95.93 \%$ obtained in 2010.

Table 1. HIV among women at the ANC unit and among HEI between 2010 and 2015

\begin{tabular}{llllll}
\hline Year & $\begin{array}{l}\text { Pregnant Women } \\
\text { registered at the } \\
\text { ANC }\end{array}$ & $\begin{array}{l}\text { Number of } \\
\text { women screened } \\
\text { at the ANC }\end{array}$ & $\begin{array}{l}\text { HIV } \\
\text { screening } \\
\text { test } \\
\text { response } \\
\text { rate }\end{array}$ & $\begin{array}{l}\text { Total HIV positive } \\
\text { pregnant women }\end{array}$ & $\begin{array}{l}\text { Proportion } \\
\text { of HIV } \\
\text { positive } \\
\text { pregnant } \\
\text { women }\end{array}$ \\
\hline 2010 & 1352 & 1297 & $95.93 \%$ & 65 & 5,01 \\
2011 & 1546 & 1314 & $84.99 \%$ & 54 & 4,10 \\
2012 & 1892 & 1707 & $90.22 \%$ & 89 & 5,21 \\
2013 & 1734 & 1733 & $99.94 \%$ & 89 & 5,13 \\
2014 & 2109 & 2112 & $100.14 \%$ & 50 & 2,36 \\
2015 & 2553 & 2550 & $99.88 \%$ & 94 & 3,68 \\
\hline
\end{tabular}

The prevalence of HIV at the antenatal care is regressing; from 5.01\% in 2010 to 3, 68\% in 2015 . Nearly all the pregnant women were screened during their pregnancy. 
DOI: 10.21522/TIJPH.2013.06.03.Art003

ISSN: $2520-3134$

The figure below represents the comparison of the proportion of HIV + women in the antenatal care and delivery room.

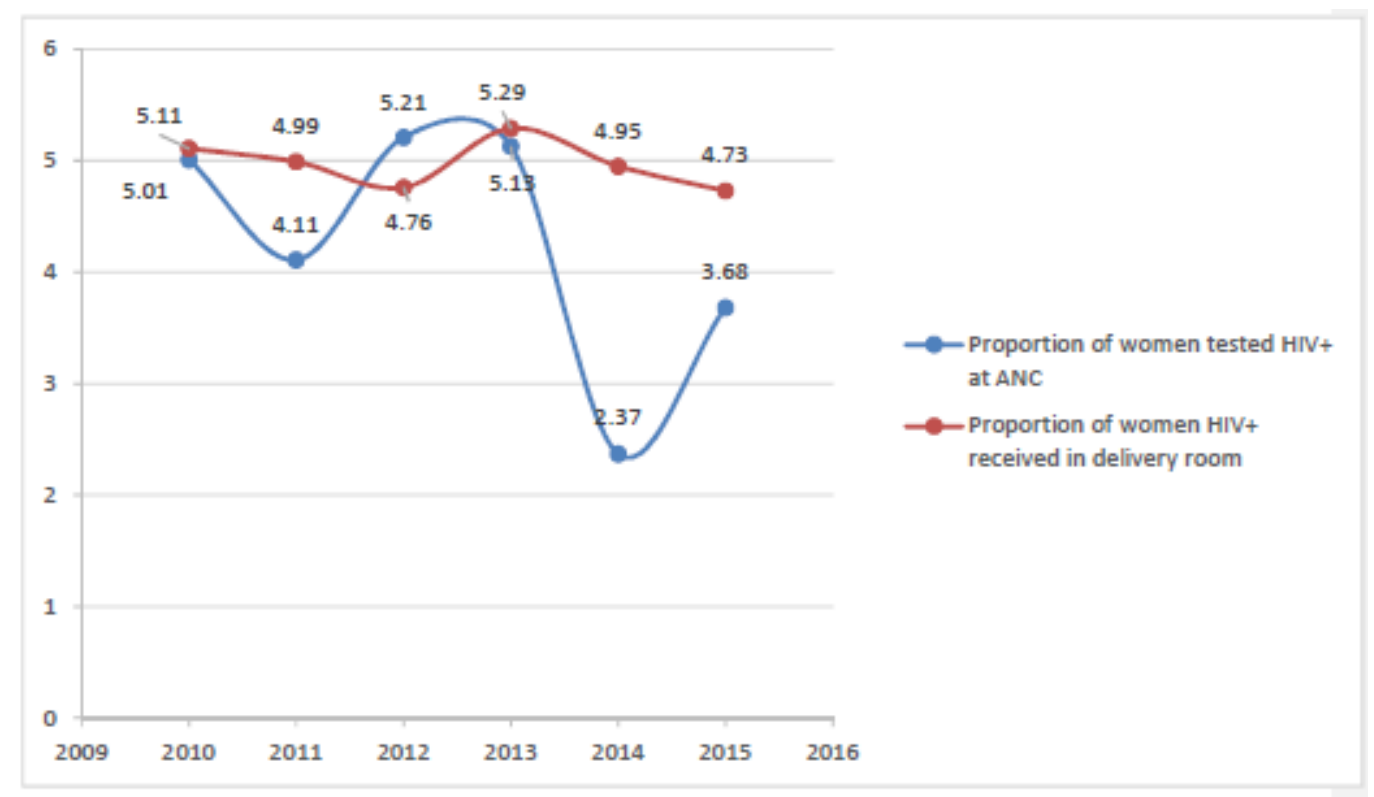

Figure 1. Comparison of the proportion of HIV + women at the antenatal care unit and in the delivery room

We observed in this figure that the proportion of HIV positive pregnant women in the delivery room (red color), is higher than the proportion at the antenatal care clinic during the same period.

\section{Proportion of HIV positive newly tested pregnant women in the delivery room}

Concerning the number of pregnant women newly screened in the delivery room, the notification really started in 2013 (seeing figure2 bellow).

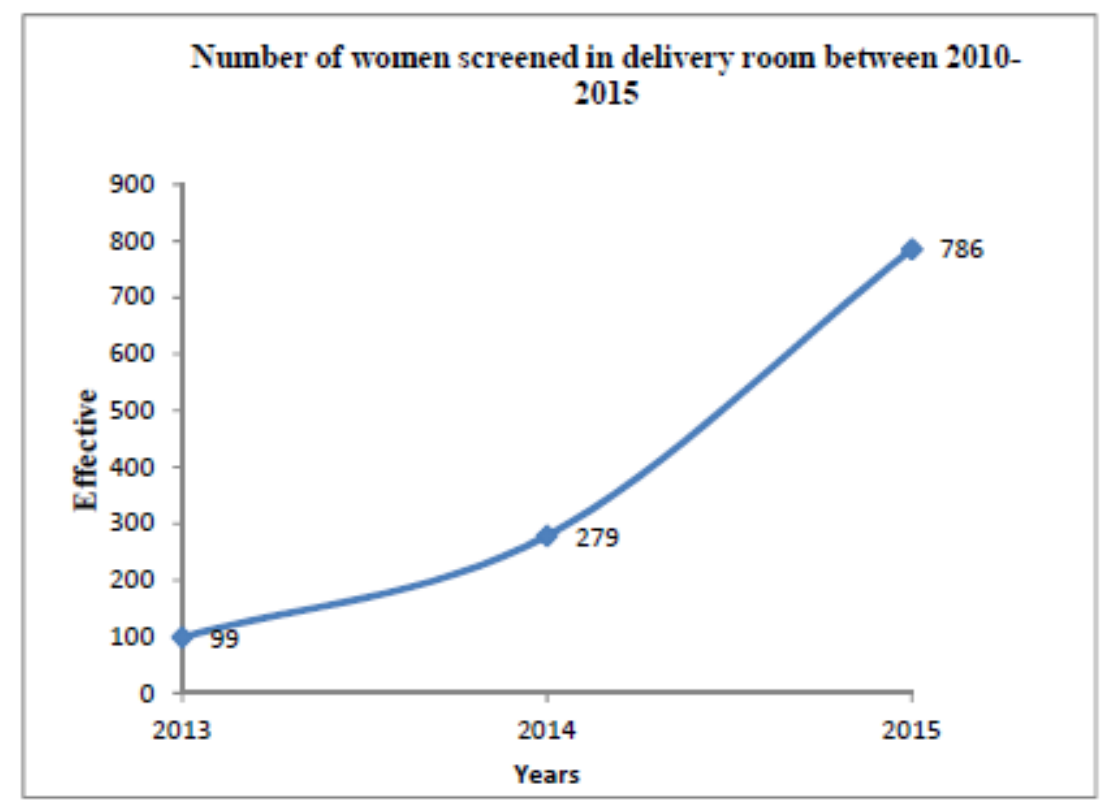

Figure 2. Number of pregnant women newly screened in the delivery room

On this figure, we observed the increasing number of newly screened pregnant women in the delivery room.

Among these women screened in delivery room, many positive cases were identified (seeing the figure 3). 


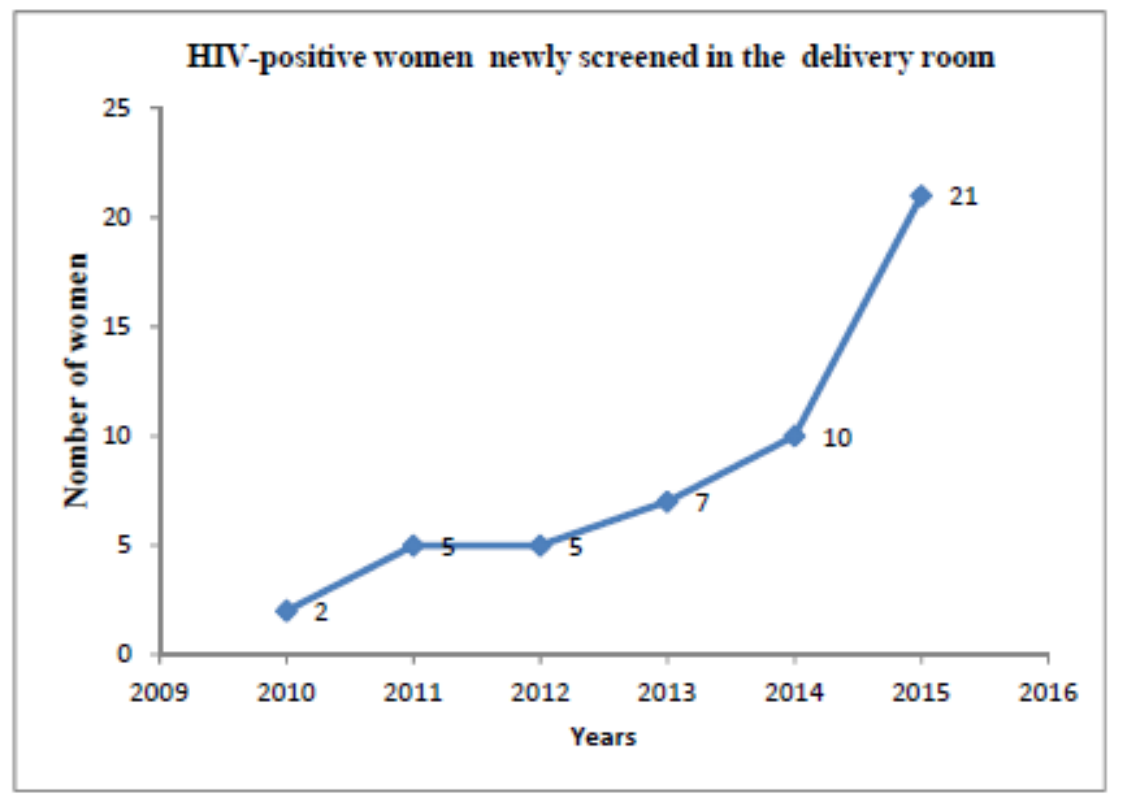

Figure 3. Number of HIV + pregnant women newly screened in the delivery room

We observed on this curve that the number of late HIV + diagnosed pregnant women is still increasing since 2014.

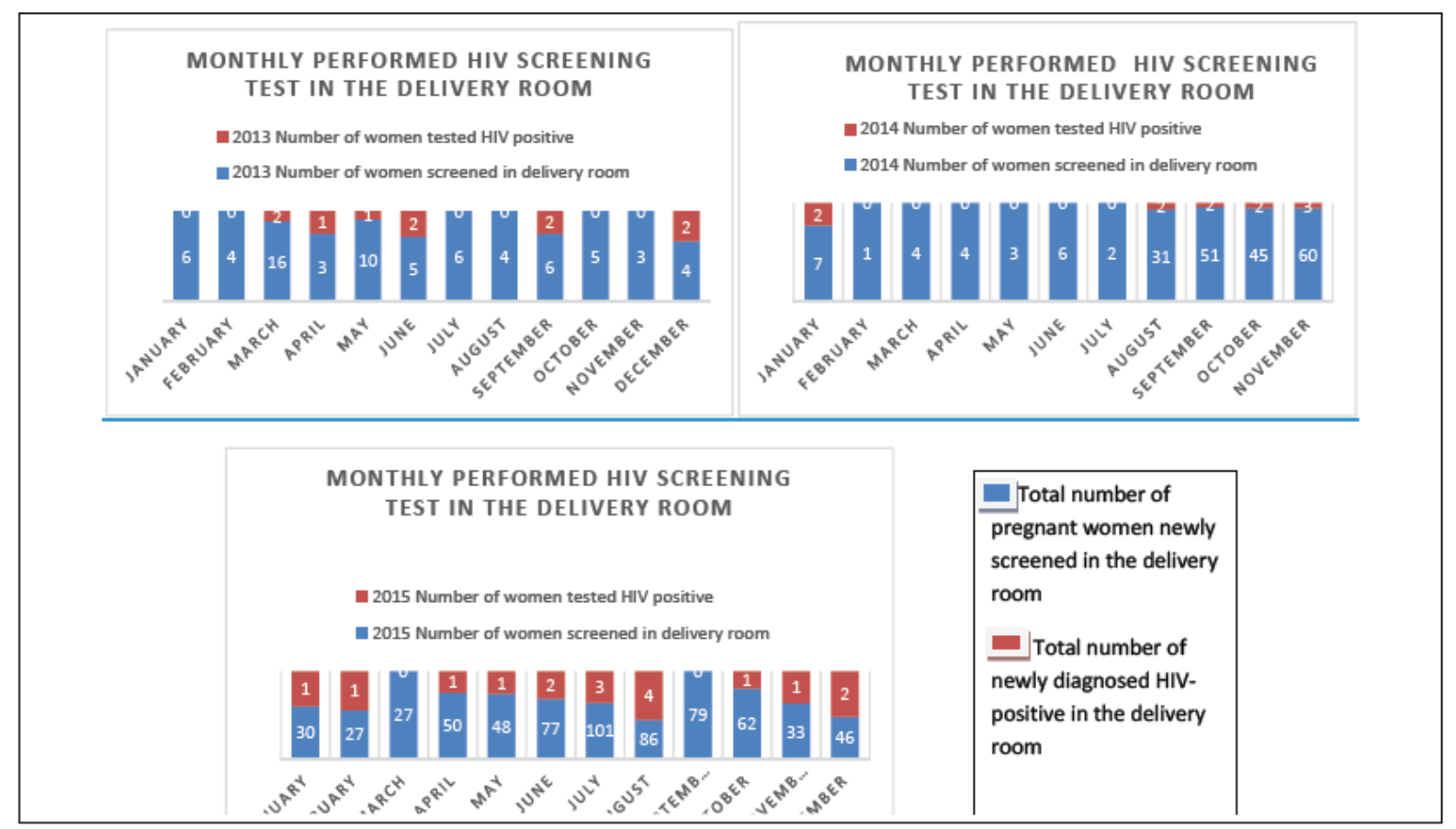


DOI: 10.21522/TIJPH.2013.06.03.Art003

ISSN: $2520-3134$

\section{Proportion of HIV + children}

The table below represents the number of HIV+ children screened between 2010 and 2015.

Table 2. Proportion of HIV + children after a Polymerase Chain Reaction (PCR)

\begin{tabular}{llllll}
\hline Year & $\begin{array}{l}\text { Number of } \\
\text { delivering }\end{array}$ & $\begin{array}{l}\text { Total number of } \\
\text { HIV-exposed } \\
\text { children }\end{array}$ & $\begin{array}{l}\text { Number of } \\
\text { PCR } \\
\text { registered }\end{array}$ & $\begin{array}{l}\text { Number of } \\
\text { missed PCR }\end{array}$ & $\begin{array}{l}\text { Number of } \\
\text { HIV + } \\
\text { children }\end{array}$ \\
\hline 2010 & 4208 & 119 & 22 & 97 & 4 \\
2011 & 4063 & 132 & 57 & 75 & 2 \\
2012 & 4888 & 129 & 28 & 101 & 3 \\
2013 & 4622 & 140 & 15 & 125 & 0 \\
2014 & 5197 & 128 & 68 & 60 & 2 \\
2015 & 4388 & 124 & 74 & 50 & 1 \\
Total & $\mathbf{2 7 3 6 6}$ & $\mathbf{7 7 2}$ & $\mathbf{2 6 4}$ & $\mathbf{5 0 8}$ & $\mathbf{1 2}$ \\
\hline
\end{tabular}

This table presents the number of HIV+ children screened between 2010 and 2015 . We observed some missing data of PCR results, of HIV positive children, Male partner's information. Only 264 1772 (34.20\%) of HIV-exposed children have their PCR results registered during our study period comparing to the number of HIV-exposed children obtained after delivering during our study period. The number of HIV + children is decreasing since 2014.

\section{Discussion}

This study aimed to describe the evolution of the PMTCT activities from 2010 to 2015 at BiyemAssi District hospital in a big town of Yaoundé in Cameroon, to address good recommendations for better health care services to the couple HIV positive mothers -babies.

We observed a large number of missing PCR tests results in the study site compare to the number of HIV-exposed children registered in the delivery room during the same period Only $34.20 \%$ of HIVexposed children have their PCR result registered, this is very low in respect to $66.7 \%$ obtained by Olana et al among 936 HIV-exposed children followed at Bishoftu, a resource limiting setting in Ethiopia. It was also found in a cohort study (from June 2013 to June 2014) of HIV+ pregnant women with lifelong ART, a poor follow-up of mother-baby pairs (Etoori et al., 2018). The missed values of PCR can be explained by the fact that there was only one national center of PCR analysis in the town, and a long turnaround time for PCR results. This cannot help to calculate the real prevalence of HIV among children born from HIV + pregnant women. As Gourlay et al observed in their study in Tanzania, data collected in Registers are sometimes missed, because health personnel are mostly occupied with nursing and without motivations, collecting data is like a surplus of work. Missed data can compromise the validity or success of the PMTCT program. 


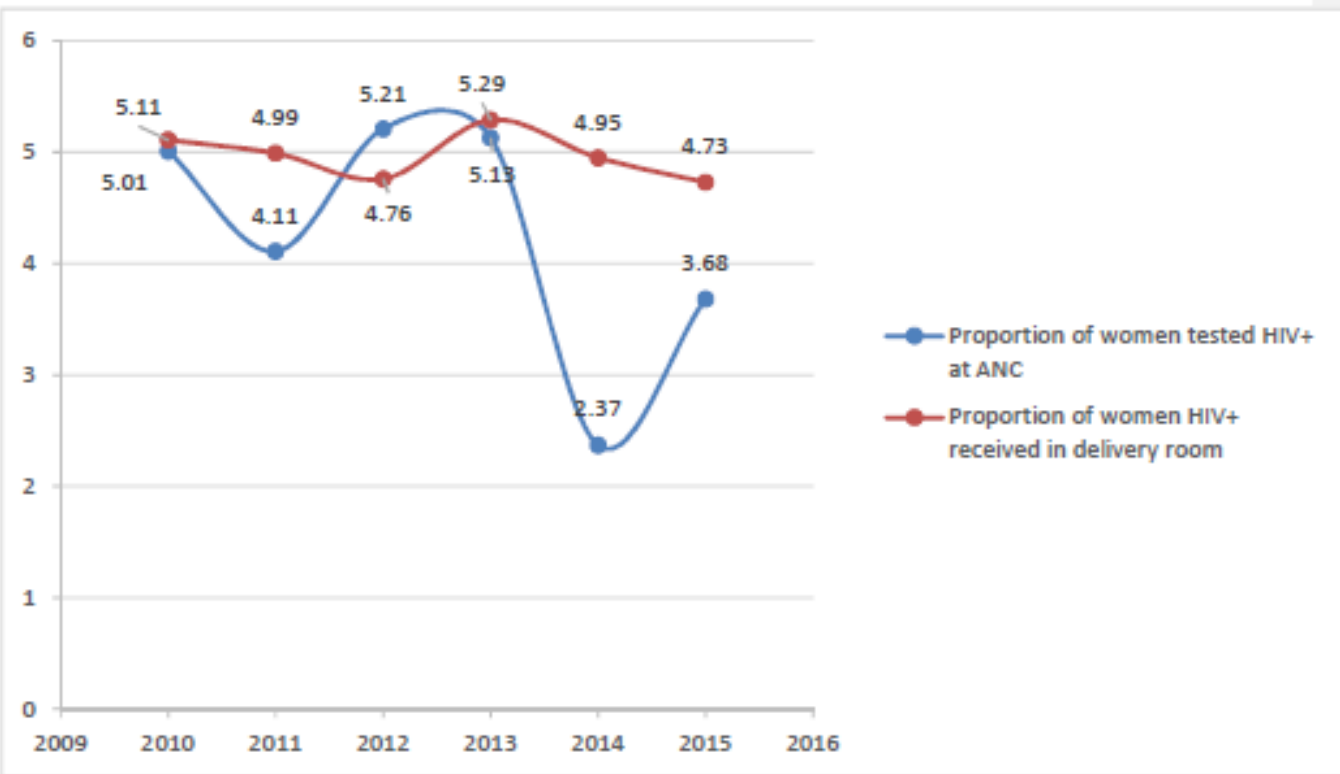

Figure 4. Monthly evolution of the HIV newly screened and positive pregnant women in the delivery room

A $99 \%$ of the response rate of the HIV test in the Biyem-assi District hospital is more appreciable than $92.40 \%$ obtained in 2013 by Ndomo Mevoula in the same town (Central hospital of Yaoundé and the university hospital center of Yaoundé). Kieffer et al. found that a rapid adoption of Option B+ led to large increases in percentage of HIV-positive pregnant women accessing ART in antenatal care (Kieffer et al., 2014). Abtew and collaborators found a response rate of $97 \%$ among pregnant women with provider -initiated HIV testing. This increasing numbers confirms a positive evolution of the education made by the health care workers. Ghoma et al also confirm the amelioration of the acceptability of voluntary HIV test among pregnant women with the increasing of general education on HIV transmission/ prevention modes (Ghoma-Linguissi et al., 2015) . Much more effort is done for the confidentiality during the follow-up of the mother.

Concerning the prevalence of HIV, we observed that 3,68\% is less than the national prevalence of HIV among pregnant women, this can be explained by the small sample size. But compare to the study of Noubiap, this prevalence is a little bite higher because Biyem-Assi is an Urban area were the high risk of HIV transmission are always recorded.

When comparing the proportion of HIV-positive pregnant women in the antenatal care and delivery room, we see that much more women are registered in the delivery room and their prevalence is higher. The increasing number of newly screened pregnant women, and the relative high proportion of HIV-positive women in the delivery room compare to the ANC unit could be explained by the fact that the biyem-assi district hospital is a reference hospital in the district. A good proportion of women came only for delivery poorly followed (insufficient counseling, resistance to the screening test), in many small clinics in or out of the district with few information about the cascade PMTCT (Antenatal PMTCT and post-partum PMTCT). As Ahmed et al. in a qualitative analysis, denial and guilt could be a reason of late initiation of ART among these pregnant women (Ahmed et al., 2017).

This increasing number can also be a proof of the better awareness of the nurses in the delivery room after multiple trainings for the option B+ implementation which started in early 2014 (Jasseron, 2013).

The decreased number of HIV - positive children observed since the beginning of the Option B+ can be the result of a good care, education, respect of the antiretroviral treatment of mother during pregnancy and the children after the delivery. This success of the multitherapy was described by Kim and collaborators in 2015 (Kim et al., 2015). 
DOI: 10.21522/TIJPH.2013.06.03.Art003

ISSN: $2520-3134$

\section{Conclusion}

At the end of this study, we attained most of our objectives; Medical personnel of the gynecology and obstetric service are aware of the importance of collecting data for analysis on PMTCT or on HIV status of children delivered from their HIV positive mothers. Better training of health professionals and good education of pregnant women on HIV increase their response to perform the HIV screening test. In the Biyem-assi District Hospital, the prevalence of the HIV among the pregnant women in the delivery room is relatively higher than the prevalence in the antenatal care unit. There is no change of the number of HIV positive women in the delivery room from pre and with the B+ option of the antiretroviral treatment, but the number of newly positive tested women in the delivery room is increasing, this demand much more vigilance to the screening in the delivery room. Many children born from HIV positive women are lost to follow up after delivery, which cannot confirm their HIV status.

\section{Difficulties}

The main difficulty that we found during the study was the counting and compiling data from registers. This method of conservation of data has a limit.

\section{Limits of the study}

As a retrospective study, our study shows some information bias due to data source. For example nothing is registered about the male partner's screening, needs, or involvement in the whole cascade of the PMTCT activities from the ANC to the post-partum consultation. Few information about the HIV positive women after the delivery room, then it is difficult to have the real prevalence of HIV among HIV - exposed children.

Another limit of this study is relative to the structure of the hospital and its activities; much more pregnant women come to deliver than for the Antenatal care. As a reference district hospital, many pregnant women come just for delivery after the antenatal care in a smaller antenatal care setting.

\section{List of abbreviations}

$\begin{array}{ll}\text { EGPAF: } & \text { Elizabeth Glaser Pediatric AIDS Foundation } \\ \text { HEI: } & \text { HIV-Exposed Infant } \\ \text { HIV: } & \text { Human Immunodeficiency Virus } \\ \text { LTFU: } & \text { Lost to follow up } \\ \text { MTCT: } & \text { Maternal to Child Transmission } \\ \text { NGO: } & \text { Non-Governmental Organization } \\ \text { PEPFAR: } & \text { President's Emergency Plan for AIDS Relief } \\ \text { PCR: } & \text { Polymerase Chain Reaction } \\ \text { PMTCT: } & \text { Prevention of Mother to Child Transmission } \\ \text { WHO: } & \text { World Health Organization }\end{array}$

\section{Recommendations}

- Organizing trainings for medical personnel of the small antenatal care settings on the antenatal care of HIV positive pregnant women, and on the cultural competency for good service quality.

- Computerizing the database in the Biyem assi District hospital for better analysis and pertinent recommendations;

- Planning interventions at the district level according to recommendations for better health services to Pregnant women

- Further studies should be made to understand reasons of the HIV seropositivity of children and the increasing number of newly tested women in the delivery room.

- Encouraging male partner of HIV- positive pregnant women with free HIV test for their early screening and their involvement to the early infant diagnosis. Good initiatives should be implemented to educate and communicate with them. 
- Developing good strategies to control the whole family (Father, mother and children) during the perinatal period to reduce the lost to follow-up in the PMTCT program. And the feedback of PCR results in the pediatric unit.

\section{Acknowledgments}

Special thanks to Dr Essama Joseph, formal Director of the Biyem -assi District Hospital for the encouragement of conducting many Institution's based studies in order to ameliorate the health service quality.

\section{References}

[1]. Abtew, S., Awoke, W., \& Asrat, A. (2015, November 9). Acceptability of provider - initiated HIV testing as an intervention for prevention of mother to child transmission of HIV and associated factors among pregnant women attending at Public Health Facilities in Assosa town, Northwest Ethiopia. BioMed Central, p. 661.

[2]. Ahmed, C. V., Jolly, P., Padilla, L., Malinga, M., Harris, C., Mthethwa, N., ... Preko, P. (2017). A qualitative analysis of the barriers to antiretroviral therapy initiation among children 2 to 18 months of age in Swaziland. African Journal of AIDS Research: AJAR, 16(4), 321-328. https://doi.org/10.2989/16085906.2017.1380677

[3]. Burton, J., Darbes, L. A., \& Operario, D. (2010). Couples-focused behavioral interventions for prevention of HIV: systematic review of the state of evidence. AIDS and Behavior, 14(1), 1-10. https://doi.org/10.1007/s10461-008-9471-4

[4]. Etoori, D., Kerschberger, B., Staderini, N., Ndlangamandla, M., Nhlabatsi, B., Jobanputra, K., ... Teck, R. (2018). Challenges and successes in the implementation of option B+ to prevent mother-to-child transmission of HIV in southern Swaziland. BMC Public Health, 18(1), 374. https://doi.org/10.1186/s12889-018-5258-3

[5]. Ghoma-Linguissi, L. S., Ebourombi, D. F., Sidibe, A., Kivouele, T. S., Vouvoungui, J. C., Poulain, P., \& Ntoumi, F. (2015). Factors influencing acceptability of voluntary HIV testing among pregnant women in Gamboma, Republic of Congo. BMC Research Notes, 8, 652. https://doi.org/10.1186/s13104-015-1651-5

[6]. Hampanda, K. M., Nimz, A. M., \& Abuogi, L. L. (2017). Barriers to uptake of early infant HIV testing in Zambia: the role of intimate partner violence and HIV status disclosure within couples. AIDS Research and Therapy, 14(1), 17. https://doi.org/10.1186/s12981-017-0142-2

[7]. Janz, N. K., \& Becker, M. H. (1984). The Health Belief Model: a decade later. Health Education Quarterly, 11(1), 1-47.

[8]. Jasseron, C. (2013). Prise en charge des femmes enceintes infecées par le VIH en France à l'ère des multithérapies: des recommandations aux pratiques. France.

[9]. Kashitala, J., Nyambe, N., Mwalo, S., Musamba, J., Chishinga, N., Kasonde, P., ... Welsh, M. (2015). Is Male Involvement in ANC and PMTCT Associated with Increased Facility-Based Obstetric Delivery in Pregnant Women? African Journal of Reproductive Health, 19(2), 117-124.

[10]. Kieffer, M. P., Mattingly, M., Giphart, A., van de Ven, R., Chouraya, C., Walakira, M., ... EGPAF Technical Directors Forum. (2014). Lessons learned from early implementation of option B+: the Elizabeth Glaser Pediatric AIDS Foundation experience in 11 African countries. Journal of Acquired Immune Deficiency Syndromes (1999), 67 Suppl 4, S188-194. https://doi.org/10.1097/QAI.0000000000000372

[11]. Kim, M. H., Ahmed, S., Hosseinipour, M. C., Yu, X., Nguyen, C., Chimbwandira, F., ... Abrams, E. J. (2015). Brief Report: Impact of Option B+ on the Infant PMTCT Cascade in Lilongwe, Malawi. Journal of Acquired Immune Deficiency Syndromes (1999), 70(1), 99-103. https://doi.org/10.1097/QAI.0000000000000692

[12]. Ministry of Public Health Cameroon. (2012). National Operational Plan for scaling up of Early Infant Diagnosis (EID), continuum of care 2013-2014, DRAFT one December 2012. Cameroon.

[13]. Moodley, T., Moodley, D., Sebitloane, M., Maharaj, N., \& Sartorius, B. (2016). Improved pregnancy outcomes with increasing antiretroviral coverage in South Africa. BMC Pregnancy and Childbirth, 16(1), 35. https://doi.org/10.1186/s12884-016-0821-3

[14]. Olana, T., Bacha, T., Worku, W., \& Tadesse, B. T. (2016). Early infant diagnosis of HIV infection using DNA-PCR at a referral center: an 8 years retrospective analysis. AIDS Research and Therapy, 13(1), 29. https://doi.org/10.1186/s12981-016-0112-0

[15]. Tariq, S., Elford, J., Cortina-Borja, M., Tookey, P. A., \& National Study of HIV in Pregnancy and Childhood. (2012). The association between ethnicity and late presentation to antenatal care among pregnant 
DOI: $10.21522 /$ TIJPH.2013.06.03.Art003

ISSN: $2520-3134$

women living with HIV in the UK and Ireland. AIDS Care, 24(8), 978-985. https://doi.org/10.1080/09540121.2012.668284

[16]. UNAIDS. (2017). UNAIDS DATA 2017.

[17]. W H O. (2013). Consolidated Guidelines on the use of Antiretroviral drugs for treating and preventing HIV infection.

[18]. WHO. (2010). PMTCT strategic vision 2010-2015 Preventing mother-to-child transmission of HIV to rach the UNGASS and Millenium Development Goals.

[19]. WHO. (2016). Consolidated Guidelines on the use of antiretroviral drugs for treating and preventing HIV infection; Recommendations for a public health approach-second edition (p. 480).

[20]. Zeng, H., Chow, E. P. F., Zhao, Y., Wang, Y., Tang, M., Li, L., .. Zhang, L. (2016). Prevention of motherto-child HIV transmission cascade in China: a systematic review and meta-analysis. Sexually Transmitted Infections, 92(2), 116-123. https://doi.org/10.1136/sextrans-2014-051877 